\title{
Competição e competitividade das empresas brasileiras
}

\author{
Judas Tadeu Grassi Mendes*
}

RESUMO - O ambiente econômico de maior competição, em especial a partir de 1994, forçou as nossas empresas a se tornarem mais competitivas, isto é, investir mais em novas tecnologias com o objetivo de aumento da produtividade e assim conseguir reduzir o custo unitário de produção e melhorar a qualidade dos produtos e serviços. Não há dúvida que os empresários brasileiros fizeram a lição de casa, apesar das condições desfavoráveis, como infraestrutura física (transporte e portos) e social (educação) aquém das necessidades do país e carga tributária de mais de um trilhão de reais por ano, sem contar a política monetária de juros elevados. O tal do custo Brasil é um grande impeditivo para a competição de nossas empresas. O que realmente falta é o setor público (leia-se governo) fazer a sua parte, reduzindo impostos, juros e melhorando a infraestrutura física e social.

Palavras-chave: Competição. Competitividade. Produtividade. Custos. Qualidade. Custo Brasil.

\section{FINALMENTE, UM AMBIENTE DE COMPETIÇÃO}

As bases do capitalismo brasileiro começaram a mudar radicalmente desde o início da década de 1990. Até então, a economia brasileira era muito fechada, a ponto de o saldo na balança comercial (que é a diferença entre as exportações e as importações) ser altamente positivo (em média, de US\$12 bilhões por ano). Esse saldo positivo ocorria, não porque o país exportasse muito, mas porque importava muito pouco. O nível de importação era pequeno (em torno de 20 bilhões de dólares por ano) pelas seguintes razões:

a) as alíquotas (leia-se: impostos) de importação eram muito elevadas, sendo que muitos produtos eram taxados em mais de $100 \%$, o que inviabilizava as importações;

b) muitos produtos não podiam ser importados em alguns períodos — não por problema de taxação, mas de proibição de importação, sob a alegação de que deveríamos proteger a indústria nacional por ser esta ainda 'infante';

c) a recessão interna em vários anos e o efeito do programa de substituição de importações ao longo da década de 1980.

\footnotetext{
* Doutor em Economia pela Ohio State University (EUA), Pós-doutor pela mesma universidade. Professor do CESUMAR e da Estação Business School. Endereço eletrônico: judas@estacaopr.com.br.
} 
Em outras palavras, o Brasil decidia proteger o produtor nacional, o qual, justamente em razão da proteção, não tinha estímulos para ser mais produtivo e eficiente. Assim, produzia produtos caros e de qualidade inferior (cabe lembrar que o presidente Collor afirmou que a indústria automobilística nacional, em 1990, produzia 'carroças'). Nesse mesmo período, os países desenvolvidos ensinavam o contrário ao defender os consumidores com a abertura da economia. É importante registrar que há muito tempo os Estados Unidos, por exemplo, importam mais de US\$ 2 trilhões por ano, ou seja, muito mais que o PIB brasileiro. Em 2008, o déficit na balança comercial norte-americana foi de US\$ 677 bilhões, o que equivale à metade do PIB brasileiro. Os países desenvolvidos preferiam fazer o que os economistas chamam de 'choque de oferta', ou seja, importar em grandes volumes, de modo que a oferta interna seja mais abundante e isso, em conseqüência, dificulte os aumentos de preços.

A estrutura básica do capitalismo brasileiro, de 1930 até os primeiros anos da década de 1990, tinha como base o seguinte tripé:

a) A empresa estatal (cujas bases foram lançadas em 1930 com Getúlio Vargas): por muitos anos, experimentamos o monopólio das estatais, que alimentavam o chamado 'estadoempresário';

b) A empresa nacional familiar (chegamos a ter grandes grupos);

c) A empresa estrangeira, que em alguns segmentos, como o automobilístico e o farmacêutico, domina totalmente o mercado nacional (a economia brasileira, até o final de 1992, era tão fechada que as importações representavam menos de 6\% do PIB, o que é um percentual muito baixo).

É importante registrar que quando um país faz defesa de seus consumidores (em vez de proteger apenas seus produtores, como fazia antes), ele força seus produtores a serem mais eficientes e mais competitivos. Efetivamente, a economia brasileira somente começou a se abrir a partir do início da década de 1990, com a redução no valor das alíquotas de importação, em especial a partir de dezembro de 1994, quando o governo baixou as alíquotas de importação de automóveis apenas 20\%, provocando em 1995 uma "enxurrada" de importação de automóveis novos. Assim, o valor importado cresceu, atingindo o máximo de US\$ 61 bilhões em 1997, para cair um pouco nos anos seguintes, sendo que no triênio 20002002 ficou próximo a US\$ 53 bilhões por ano. Nos últimos anos (principalmente a partir de 2005, por conta do dólar que se manteve baixo), as importações cresceram muito, a ponto de chegar ao recorde de US\$173,1 bilhões em 2008. É importante registrar que essa abertura da 
economia 'forçou' as empresas brasileiras a se tornarem mais competitivas, uma vez que, até então, era mais fácil 'formar o preço' no mercado. Em um ambiente de pouca competição e estrutura de mercado oligopolizado, é fácil perceber que os preços de mercado resultavam da soma de custos de produção (elevados) com grandes margens de lucros.

Neste ambiente, a equação de custo, margem e preço era a seguinte:

Custo médio de produção + a margem de lucro $=$ preço para o consumidor

As empresas brasileiras, na verdade, experimentaram e continuam experimentando cinco processos, quais sejam: a globalização, a abertura da economia, a estabilização de preços (ou seja, Plano Real), a privatização e a crescente conscientização dos consumidores brasileiros (com base no Código de Defesa do Consumidor, de 1991). Esses cinco processos têm provocado importantes mudanças positivas nos processos produtivos das empresas brasileiras, de modo que elas têm aumentado a produção, reduzido o custo unitário e melhorado a qualidade.

\section{O CÍRCULO VICIOSO DA COMPETITIVIDADE}

A abertura da economia, a partir de 1994, calcada de um lado com a redução de impostos de importação e de outro lado com o câmbio mantido próximo da unidade, forçou as empresas brasileiras a se tornarem mais competitivas. Para ser competitiva, uma empresa precisa dominar três dimensões:

1. Investir em tecnologia no processo (sobre isso discutiremos mais adiante) para conseguir maior produtividade, o que significa, por exemplo, produzir mais de um produto por unidade de fator (mão-de-obra ou hora-máquina). Por exemplo, um grande fabricante de geladeiras no Brasil, há dez anos produzia apenas 1,3 geladeiras por trabalhador/dia, mas hoje consegue produzir 4,0 geladeiras por trabalhador-dia. Isso foi possível graças a novos sistemas de automação, ou seja, novas tecnologias.

2. A maior produtividade dos fatores de produção resulta em menor custo unitário (ou médio), pois a relação entre este e a produtividade é inversa — produzir mais barato somente é possível com maior produtividade. É importante registrar que a única variável nas mãos dos empresários é o custo unitário, pois o preço já não mais depende deles, mas sim dos consumidores.

3. Alcançar melhor qualidade dos produtos. Em termos de qualidade, ainda temos muito que melhorar. Basta dizer que a indústria de fiação e tecelagem ainda prefere o algodão importado, porque a fibra é melhor; que a indústria de panificação prefere o trigo importado 
ou que o consumidor norte-americano prefere o café colombiano considerado por eles como de melhor qualidade.

A Figura 1 mostra o círculo virtuoso de competitividade, cujo esquema é autoexplicativo, uma vez que o início do processo pode começar em qualquer ponto.

FIGURA 1 - CÍRCULO VICIOSO DA COMPETITIVIDADE

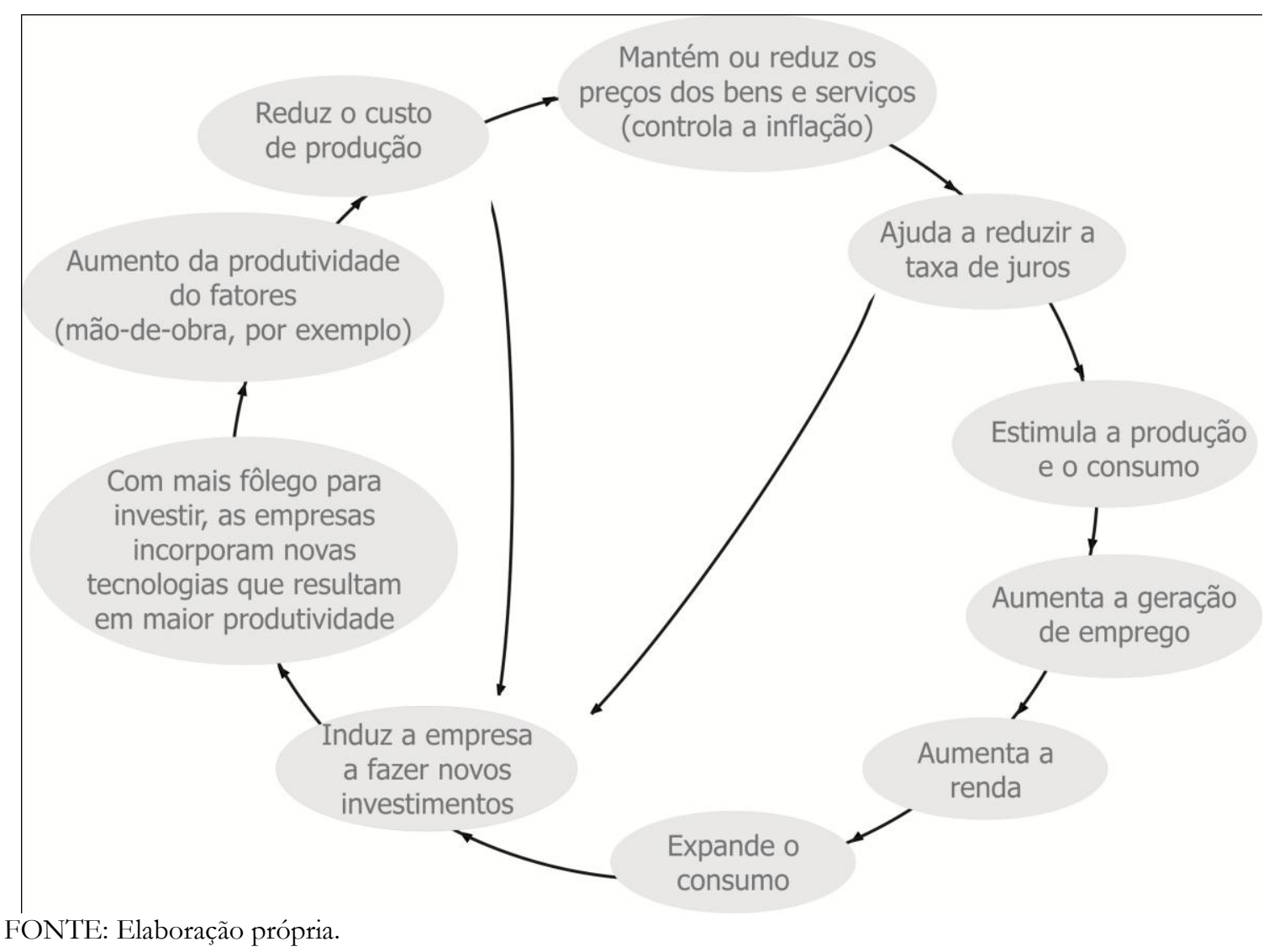

\section{A EMPRESA DE SUCESSO}

A empresa competitiva está no caminho para se tornar também uma empresa de sucesso. A diferença é que esta, além de ser competitiva (ou seja, produz barato), gera também produtos diferenciados. Com produtos diferenciados, a empresa pode cobrar mais por eles, ou seja, isso afeta positivamente os preços de venda dos seus produtos. Ter um produto diferenciado é o caminho não só para conquistar consumidores, mas principalmente para fidelizá-los. No ambiente atual de maior competitividade, houve inversão da equação, pois o lucro passou a ser dependente do preço que os consumidores estão dispostos a pagar e dos custos de produção. $\mathrm{Na}$ verdade, o produtor só tem mesmo controle (ou pelo menos deveria ter) dos custos de produção, e é por isso que ele precisa investir em tecnologia para 
reduzir o custo médio de produção, uma vez que está ficando mais difícil determinar preço de mercado. Assim, a equação do lucro (como em qualquer país desenvolvido) passou a ser:

$$
\text { Lucro }=\text { Preço de venda }- \text { custo médio de produção }
$$

Portanto, a empresa de sucesso é aquela que produz barato, algo diferenciado. Desse modo, o lucro unitário é maior.

\section{DESAFIOS DE SER COMPETITIVA NO BRASIL}

Se a palavra de ordem no mundo dos negócios é a empresa ser competitiva, estar instalada no Brasil passa a ser um desafio muito grande, por causa do famoso "custo Brasil".

Por "custo Brasil" entende-se um conjunto de gastos que incorrem as empresas que têm suas plantas industriais e comerciais instaladas no país e cujos valores são muito maiores do que enfrentam as empresas semelhantes instaladas em outros países. Basicamente, podemse incluir esses custos em três grandes grupos: os ligados à infraestrutura, os de origem tributária e os relacionados à questão monetária.

Os custos que têm origem na infraestrutura são transporte e portos, por exemplo. $\mathrm{Na}$ questão do transporte, o Brasil, infelizmente, merece o livro dos recordes (negativos) pelo simples fato de ter, historicamente, optado pelo transporte rodoviário como seu principal meio, que é o segundo mais caro, perdendo apenas para o transporte aéreo. Isso faz com que os custos de transporte sejam elevados em demasia. Os meios ferroviário e fluvial (sem falar na enorme costa marítima que este país tem) praticamente não foram explorados e só recentemente, por causa da privatização, tem ocorrido algum avanço. Apenas para fins de comparação: com praticamente a mesma dimensão dos Estados Unidos, o Brasil tem cerca de 22 mil quilômetros de ferrovias (a maioria da época do Império), enquanto os Estados Unidos dispõem de mais de 300 mil quilômetros. Por falar em ferrovias, o que dizer da mistura de bitolas largas (para altas velocidades) e bitolas estreitas (para velocidades reduzidas), estas usadas principalmente perto da fronteira com a Argentina, a fim de dificultar uma possível invasão no caso de uma eventual guerra com os platinos? Era assim que alguns "estratégicos" do governo pensavam no passado. E o que dizer das inacabadas ferrovias Madeira-Mamoré ou Ferrovia do Aço? Os Estados Unidos utilizam o rio Mississipi, por meio do qual exportam mais de 100 milhões de toneladas de grãos (produzidos no Meio-Oeste, o famoso corn belt) há mais de cem anos, enquanto, apenas recentemente, descobrimos que o rio Madeira (interligando Rondônia e região ao rio Amazonas e, portanto, ao oceano Atlântico) poderia ser um excelente e barato meio de transporte de grãos das novas fronteiras agrícolas. 
Ainda quanto aos custos ligados à infraestrutura, têm-se os portos, cujos custos, comparados com portos de outros países, são muito maiores. Basta citar o caso dos práticos (técnicos especializados na orientação do atracamento dos navios), que, para cada navio que atraca, cobram cerca de US\$ 4 mil; em Paranaguá, existem dezoito práticos, cujos salários médios ultrapassam $\mathrm{R} \$ 40$ mil por mês.

Os custos Brasil relacionados à questão tributária penalizam muito as empresas brasileiras. Afinal, são 62 tipos de impostos e contribuições, que juntos representam mais de um terço do produto interno bruto, quando se poderia ter menos de dez impostos e contribuições. Os brasileiros pagam mais de R 1 trilhão por ano em impostos.

Por último, mas não menos importantes, estão os custos ligados aos juros (questão de origem monetária), que se encontram entre os mais elevados do mundo. Enquanto uma empresa nos Estados Unidos consegue recursos financeiros para o investimento com juros em torno de 3\% ao ano, no Brasil, uma empresa concorrente tem de pagar quase essa taxa por mês.

Além do custo Brasil, há pelo menos três outros fatores que dificultam as empresas brasileiras de serem competitivas, que são: baixo investimento em ciência e tecnologia, baixo nível educacional e a burocracia do setor público.

No tocante ao baixo investimento em ciência e tecnologia, pode-se dizer, a título de comparação, que no Japão, os investimentos em ciência e tecnologia ultrapassam US\$600,00 por habitante por ano; na Alemanha, são superiores a US\$ 500,00; nos Estados Unidos, são de US\$ 500,00; no Brasil, entretanto, esse investimento é de apenas US\$ 40,00 por habitante por ano. No nosso país, as empresas privadas respondem por apenas 30\% dos gastos anuais em pesquisa ( $70 \%$ são do governo) e, no total, os investimentos somam $0,5 \%$ do PIB. Nos países desenvolvidos, porém, aplicam-se 2,8\% do PIB e, do total aplicado, as empresas contribuem com 60\% (40\% vem do governo). Não há a menor dúvida de que está havendo mudanças nesse aspecto no Brasil, nos últimos anos, uma vez que, por necessidade, as empresas estão começando a investir cada vez mais em ciência e tecnologia - é possível que o percentual de investimento da iniciativa privada esteja ao redor de $40 \%$.

Com relação ao baixo nível educacional, pode-se dizer que a grande maioria dos problemas que afetam a sociedade brasileira tem origem no baixo nível educacional de seu povo. Infelizmente, a educação nunca recebeu dos governos a atenção que deveria. Nas escolas públicas de ensino fundamental e médio, os investimentos por aluno não chegam a R\$ 5,00 por dia, o que é vergonhoso. Para fins de comparação, nos Estados Unidos, esse valor 
supera US\$ 5 mil por aluno por ano. A grande transformação ocorrida no Japão, ao longo do século XX, deve-se única e exclusivamente aos investimentos maciços em educação básica. Cabe lembrar a chamada Revolução Meiji, em 1906, cujo principal objetivo foi “apostar" tudo na educação, de tal maneira que, ao completar 15 anos, todo cidadão japonês deve obrigatoriamente ter nove anos de escolaridade, em tempo integral (das 8 às 17 horas). Ou seja, em termos de educação, o cidadão precisa ter quantidade e qualidade e isso é tudo o que não há no Brasil. Basta ver a avaliação recente do ENEM que evidencia a péssima qualidade do ensino medido das escolas públicas.

Em média, o jovem brasileiro, ao completar 15 anos, não chega a ter quatro anos de escolaridade (menos da metade do jovem japonês) e com apenas 3,7 horas por dia (menos que as 4 horas que, por lei, seriam obrigatórias). É importante lembrar que o desenvolvimento econômico e social de um país depende cada vez mais do domínio da ciência e da tecnologia, e estas, por sua vez, dependem da educação. Somente a educação será capaz de provocar as mudanças socioeconômicas de que o Brasil tanto necessita. Entristece ver que os governos investem tão pouco em educação básica, mas que o governo federal gasta, com juros da enorme dívida interna (que já ultrapassa $\mathrm{R}$ \$ 1,4 trilhão), mais de $\mathrm{R}$ \$ 150 bilhões por ano (algo como seis vezes mais do que investe em educação). É claro que os bancos agradecem penhoradamente! Ou seja, dinheiro existe, mas não para a educação. Para se ter uma idéia, somente nos seis primeiros anos, o governo Lula pagou R $\$ 922$ bilhões em juros. É uma pena.

Em suma, o custo Brasil, por ser tão elevado, reduz a competitividade das empresas brasileiras, e isso explica, em grande parte, por que o nosso país exporta menos de US\$200 bilhões por ano, enquanto a China, que há 20 anos exportava menos que o Brasil, exportou em 2008 mais de US\$ 1,2 trilhão, sem contar Hong Kong (cidade com menos de 7 milhões de pessoas), que exporta mais do que o Brasil. Assim, reduzir o custo Brasil é exportar mais, gerar mais empregos, maior renda e mais impostos aqui dentro.

Apesar destas restrições, cabe registrar que as empresas brasileiras fizeram grandes avanços na direção da competitividade, ou seja, o ambiente de maior concorrência forçou as nossas empresas a investir mais em novas tecnologias, aumentar a produtividade, reduzir o custo unitário (com conseqüências positivas sobre a inflação) e a melhorar a qualidade. É uma pena que o governo não tenha feito a sua parte, cobrando menos impostos, tendo maior controle sobre as finanças públicas (leia-se: menos gastança) e investindo mais em infraestrutura física (transporte e portos) e social (saúde, educação e segurança). 
